\title{
Metabolic syndrome is independently associated with increased 20-year mortality in patients with stable coronary artery disease
}

Arwa Younis ${ }^{1 *+}$, Anan Younis $^{1+}$, Boaz Tzur ${ }^{1}$, Yael Peled ${ }^{1}$, Nir Shlomo ${ }^{1}$, llan Goldenberg ${ }^{1,2,4}$, Enrique Z. Fisman ${ }^{2,3}$, Alexander Tenenbaum ${ }^{1,2,3}$ and Robert Klempfner ${ }^{1,2}$

\begin{abstract}
Background: Data regarding long-term association of metabolic syndrome (MetS) with adverse outcomes are conflicting. We aim to determine the independent association of MetS (based on its different definitions) with 20 year all-cause mortality among patients with stable coronary artery disease (CAD).

Methods: Our study comprised 15,524 patients who were enrolled in the Bezafibrate Infarction Prevention registry between February 1, 1990, and October 31, 1992, and subsequently followed-up for the long-term mortality through December 31, 2014. MetS was defined according to two definitions: The International Diabetes Federation (IDF); and the National Cholesterol Education Program-Third Adult Treatment Panel (NCEP).

Results: According to the IDF criteria 2122 (14\%) patients had MetS, whereas according to the NCEP definition 7446 (48\%) patients had MetS. Kaplan-Meier survival analysis showed that all-cause mortality was significantly higher among patients with MetS defined by both the IDF (67 vs. 61\%; log rank-p < 0.001) as well as NCEP (67 vs. 54\%; log rank-p $<0.001$ ) criteria. Multivariate adjusted mortality risk was $17 \%$ greater [Hazard Ratio (HR) 1.17; 95\% Confidence Interval (CI) 1.07-1.28] in patients with MetS according to IDF and 21\% (HR 1.21; 95\% Cl 1.13-1.29) using the NCEP definition. Subgroup analysis demonstrated that long-term increased mortality risk associated with MetS was consistent among most clinical subgroups excepted patients with renal failure ( $p$ value for interaction $<0.05$ ).

Conclusions: Metabolic syndrome is independently associated with an increased 20-year all-cause mortality risk among patients with stable CAD. This association was consistent when either the IDF or NCEP definitions were used. Trial registration retrospective registered
\end{abstract}

Keywords: Metabolic syndrome, Stable coronary artery disease, Prognosis, All-cause mortality, Long term outcomes

\section{Background}

The metabolic syndrome (MetS) is a constellation of cardiovascular risk factors centered around obesity, abnormal glucose metabolism, hypertension and atherogenic dyslipidemia $[1,2]$.

These risk factors tend to cluster together in patients, and when they do, they substantially increase the risk for

\footnotetext{
*Correspondence: or.younis@gmail.com

${ }^{\dagger}$ Arwa Younis and Anan Younis contributed equally to this work

1 The Leviev Heart Center, Sheba Medical Center, Tel Hashomer, Sheba Road 2, 52620 Ramat Gan, Israel

Full list of author information is available at the end of the article
}

the development of cardiovascular disease [2]. The prevalence of the MetS is increasing, coincident with increasing levels of obesity related to sedentary lifestyles and poor nutrition habits [3-6].

The association of the MetS with increased risk of adverse cardiovascular outcomes, morbidity and mortality is well established [7-13]. However, controversy remains regarding independent character of this association as well as regarding the additional value of the MetS in the risk estimation on top of its individual components. Furthermore, recent studies showed that MetS is associated with an increased risk of cardiovascular mortality and re-infarction in patients with cardiovascular 
disease [14, 15], however, these studies are mostly limited to patients after a recent acute coronary syndrome (ACS) or after revascularization, and there is limited data regarding patients with stable coronary disease without revascularization procedures [16]. Furthermore, to date the follow-up period in the majority of studies exploring the association of MetS and mortality is less than 3 years [16-21] and these studies have predominantly explored cardiovascular mortality and not all-cause mortality as their primary outcome [16-21].

Thus, limited data exist regarding the association between the presence of MetS and long-term all-cause mortality among patients with stable coronary artery disease (CAD), especially among those who have not undergone prior coronary revascularization or recent ACS. It is unclear whether this association is independent following adjustment for other comorbidities and clinical characteristics. Furthermore, the principle definitions of MetS have not been compared in large cohorts of patients with stable CAD.

Accordingly, the aims of the present study were to: (1) determine the independent association of MetS as defined by the National Cholesterol Education Program (NCEP) vs. the International Diabetes Federation (IDF) criteria with 20-year all-cause mortality outcome; (2) evaluate the heterogeneity of the association between MetS and mortality in important subgroups of patients.

\section{Methods}

\section{Study population}

The present study population comprised patients who were screened for participation in the Bezafibrate Infarction Prevention (BIP) trial between February 1990 and October 1992 and enrolled in the BIP Registry. The design and rationale of the BIP Registry and study were published previously [22, 23]. Of the 15,524 screened patients, only $3090(20 \%)$ proceeded to be randomized in the prospective interventional 6-year BIP study that compared Bezafibrate to placebo. As the intervention period ended more than 15 years ago we decided to include these patients in our analysis cohort.

Briefly, BIP Registry included 15,524 patients aged 40-74 years with stable CAD fulfilling the following inclusion criteria: (1) documented myocardial infarction (MI) in the previous 5 years, (2) symptomatic stable angina pectoris and either a positive myocardial ischemia by radio-nuclear-scintigraphy, or $\geq 60 \%$ stenosis of 1 of the major coronary arteries, demonstrated by coronary angiography, or (3) documented percutaneous transluminal coronary angioplasty (PTCA) or coronary artery bypass grafting (CABG) operation in the preceding 6 months. Exclusion criteria included: diabetes mellitus requiring the use of insulin, severe heart failure, unstable angina, hepatic or renal failure, and current use of lipidmodifying drugs.

All medical examination and biochemical blood-tests, historical medical data, as well as data on drug therapy were prospectively recorded and all vital signs measured.

After exclusion of those patients with missing laboratory values the final data set for the current study comprised of 15,413 patients. Median follow up duration was $20 \pm 5$ years.

The study was approved by the institute's internal review board and was performed according to the principles expressed in the Declaration of Helsinki and the ethics policy of the institute.

\section{Metabolic syndrome definitions}

Currently, there are two major definitions for MetS: the International Diabetes Federation (IDF) [24, 25] and National Cholesterol Education Program-Third Adult Treatment Panel (NCEP) [26]. Accordingly, study patients were categorized by the presence or lack of MetS by the two separate definitions.

\section{Diagnosis criteria}

Patients who presented with three or more of the following five risk factors were defined as having MetS according to the NCEP:

1. Central obesity defined as waist circumference greater than established ethnicity specific values. Since the data regarding waist circumference were not available, for purposes of this analysis we used the accepted body mass index (BMI) above 30 as a criterion for classifying patients as obese $[25,27]$.

2. Low high-density lipoprotein (HDL) $<50 \mathrm{mg} / \mathrm{dL}$ among women, and $<40 \mathrm{mg} / \mathrm{dL}$ among men.

3. Elevated fasting plasma triglycerides (TG) $\geq 150 \mathrm{mg} /$ $\mathrm{dL}$, or specific treatment for this lipid abnormality.

4. Elevated systolic blood pressure $\geq 130 \mathrm{~mm} \mathrm{Hg}$, or diastolic value $\geq 85 \mathrm{~mm} \mathrm{Hg}$, or treatment of previously diagnosed hypertension.

5. Elevated fasting plasma glucose (FPG) $\geq 100 \mathrm{mg} / \mathrm{dL}$ or previously diagnosed diabetes mellitus.

The definition of the MetS according to the IDF has some modifications as it requires central obesity as an obligatory criterion, and two or more of the other criteria as detailed above. Central obesity can be substituted by BMI $>30[25,27,28]$.

Patients were defined as diabetics based on their medical record diagnosis as prospectively coded at study entry. The same method was applied to the definitions of hypertension, smoking status and other elements of medical history. Patients with diabetes were considered 
in this analysis as having impaired fasting glucose even if their point measurement of FPG was below $100 \mathrm{mg} / \mathrm{dL}$.

\section{Laboratory methods}

Blood samples were drawn after at least $12 \mathrm{~h}$ of fasting. Cooled samples, collected in the 18 participating centers using standard equipment and procedures, were transferred to the study's central laboratory. All analyses were performed on a Boehringer Hitachi 704 random access analyzer using Boehringer diagnostic kits. Detailed data on laboratory methods were given in a previous report [29].

\section{Primary end point}

The primary end point of this study was all-cause mortality. Mortality data was obtained by matching the patient's identification numbers with their vital status available in the National Population Registry of Israel. Each match record was checked for correct identification by matching the date of birth coded during survey enrollment with the date of birth available from the national registry. Patients with missing values or inconsistent matching were excluded from the present analysis $(n=111)$.

\section{Statistical analysis}

Continuous variables are expressed as mean \pm standard deviation (SD), and categorical data are summarized as percentages. The clinical characteristics of the patients at baseline by presence of the MetS were compared with the use of the unpaired $t$ test for continuous variables or Mann-Whitney as appropriate, and the Chi square test for categorical variables.

The Kaplan-Meier method was used to calculate cumulative survival curves for patients with and without MetS and the curves were compared using a Log rank test.

Multivariate Cox proportional hazard regression modeling was used to assess the independent effect of the MetS on the primary end point of all-cause mortality. The following covariates were introduced using the best subset method, following a univariate analysis of all relevant variables: age, gender, smoking status, creatinine concentration, diagnosis of diabetes mellitus (DM), hypertension, heart failure NYHA $>2$, previous MI or past cerebrovascular accident (CVA). We additionally performed multivariate analysis as described above and included medication (anti-platelets, nitrates, calcium channel blockers, beta blockers and diuretics) as additional covariates.

Proportionality of hazard assumption was verified using Schoenfeld residuals and the log minus log (LML) method. We additionally performed a sensitivity analysis excluding patients randomized to the BIP randomized study $(\mathrm{n}=3090)$.
In order to further explore the independent risk associated with the presence of MetS in pre-specified patient subgroups we performed interaction term analysis by the introduction of an MetS-by-risk-subgroup interaction-term to the multivariate age adjusted Cox model (MetS by age interaction was not further adjusted). The following pre-specified subgroups were explored: age $\geq 65$ years, gender, prior MI, renal dysfunction [serum creatinine $>1.5 \mathrm{mg} / \mathrm{dL}]$, and New York Heart Association (NYHA) class $>2$. Interaction analysis is graphically presented in the form of a Forest plot.

Furthermore, in order to confirm our findings, an additional sensitivity analysis was performed, in which the waist circumference $\backslash B M I$ criteria were excluded, and the diagnosis of MetS was made if patients had two out of the four remaining criteria.

Statistical significance was declared for a two-sided $\mathrm{p}<0.05$. The statistical analysis was performed with IBM SPSS version 20.0 (Chicago, IL, USA) and SAS version 9.2 (SAS institute Inc.) statistical software.

\section{Results}

Based on the criteria of the IDF 2122 (14\%) patients had MetS, compared to 13,291 (86\%) patients without the MetS, whereas based on the NCEP criteria 7446 (48\%) patients had MetS, and 7967 (52\%) were considered without. Baseline characteristics of patients with and without MetS according to both definitions are summarized in Table 1.

As expected, patients with MetS had an adverse clinical and biochemical profile, including higher incidence of diabetes, hypertension, hypercholesterolemia, and NYHA class $>2$. According to the IDF definition, patients with the MetS were slightly younger, with a male predominance, and had slightly lower serum creatinine concentration compared to patients without MetS (Table 1).

Prevalence of past CVA, and chronic obstructive lung disease (COPD) were similar. Low-density lipoprotein (LDL) levels and history of past MI were similar when MetS was defined by IDF criteria. When MetS was defined according to the NCEP criteria, past MI rates was similar between groups, however, LDL levels were higher in the MetS group vs. those without MetS $(156 \pm 36$ vs. $154 \pm 33, \mathrm{p}<0.001$ ).

Patients with the MetS were significantly more likely to receive beta-blockers, diuretics, calcium channel blockers and nitrates, and less likely to receive antiplatelet therapy (Table 1).

We further compared the individual components of MetS defined by the NCEP vs. the IDF criteria (Additional file 1: Table S1). Patients categorized according to the NCEP definition were more likely to have other metabolic components (hypertension, IFG, 
Table 1 Baseline characteristics of the study population by the two metabolic syndrome definitions

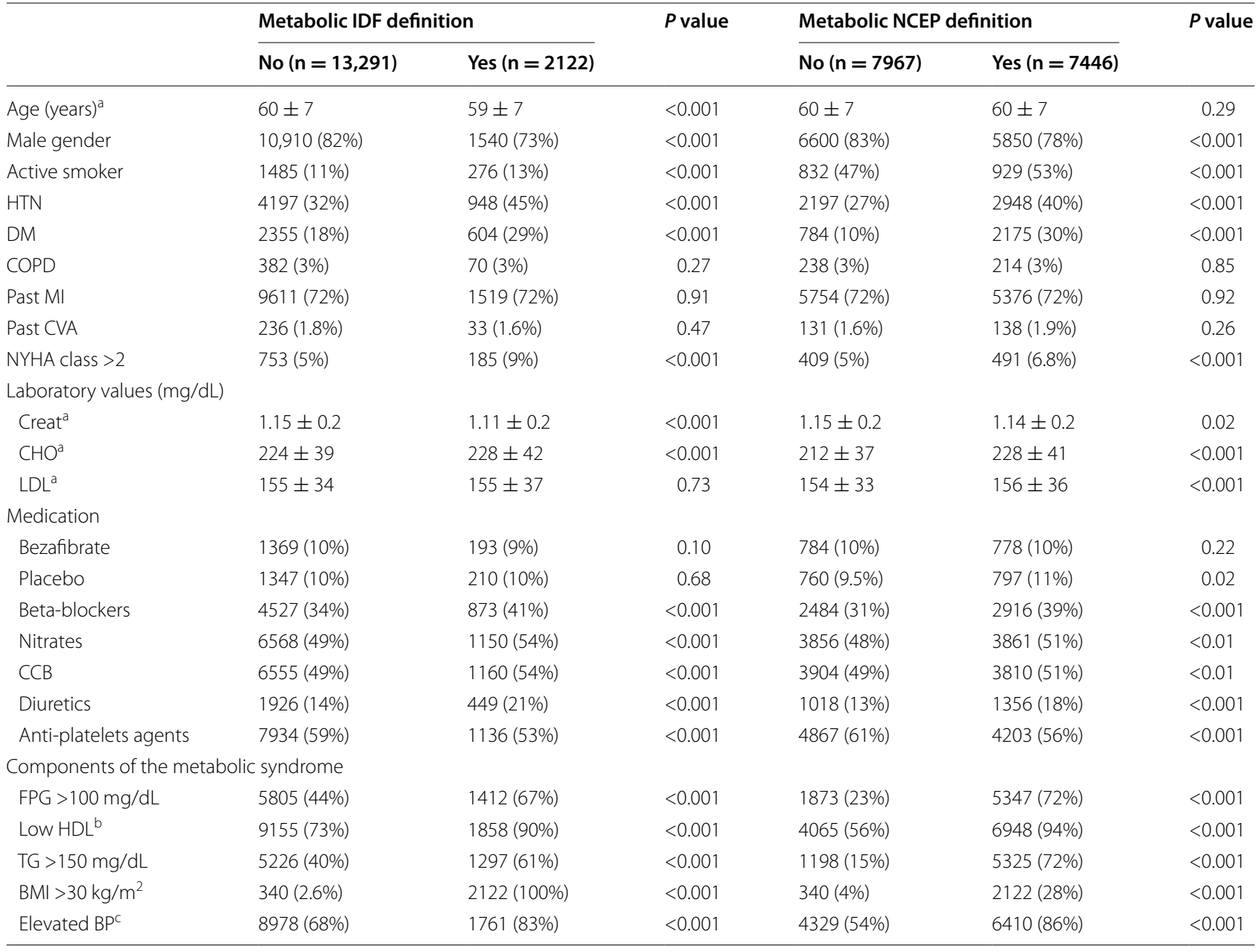

$B M I$ body mass index; $B P$ blood pressure; $C H O$ total cholesterol; $C O P D$ chronic obstructive pulmonary disease; Creat creatinine; $C V A$ cerebral vascular accident; $D M$ diabetes mellitus; FPG fasting plasma glucose; HDL high-density lipoprotein; $H T N$ hypertension; IDF International Diabetes Federation; $L D L$ low density lipoprotein; $M I$ myocardial infarction; NCEP National Cholesterol Educational Program; NYHA New York Heart Association; TG triglycerides

a Continuous variables are reported as mean \pm standard deviation if normally distributed; otherwise, as median with 25 th-75th range. Categorical variables are reported as numbers (\%)

b Low $\mathrm{HDL}$ defined as $\mathrm{HDL}<40 \mathrm{mg} / \mathrm{dL}$ in males and $\mathrm{HDL}<50 \mathrm{mg} / \mathrm{dL}$ in females

c Systolic blood-pressure $>130 \mathrm{mmHg}$ or/and diastolic blood-pressure $>85 \mathrm{mmHg}$

hypertriglyceridemia and low HDL) with the exception of BMI $>30$ that was present in only $28 \%$ of the NCEP group vs. $100 \%$ of the IDF group (all p value $<0.001$ ).

\section{Long-term mortality by the presence of MetS}

Kaplan-Meier survival analysis showed that at 20 years of follow-up all-cause mortality probability was significantly higher among patients with MetS vs. those without MetS (Fig. 1). When defined by the IDF criteria the respective cumulative mortality probability at 20 years were 1429 $(67 \%)$ and $8095(61 \%)(p<0.001$ for the overall comparison during follow-up; Fig. 1a), and when defined by the NCEP criteria the respective rates were 4987 (67\%) and
4329 (54\%) ( $\mathrm{p}<0.001$ for the overall comparison during follow-up; Fig. 1b). Notably, separation in event rates between MetS and non-MetS patients appeared after approximately one year and was sustained thereafter.

Consistently, multivariate adjusted for: age, gender, smoking status and major comorbidities (Creatinine $>1.5 \mathrm{mg} / \mathrm{dL}$, DM, HTN, past MI, previous CVA and NYHA >2), MetS defined by the NCEP was associated with a significant $21 \%$ independent increased mortality risk (HR 1.21; 95\% CI 1.13-1.29; Table 2a) whereas MetS defined by the IDF, was similarly independently associated with a $17 \%$ increased all-cause mortality risk (HR 1.17; 95\% CI 1.07-1.28; Table 2b). Consistent results were 


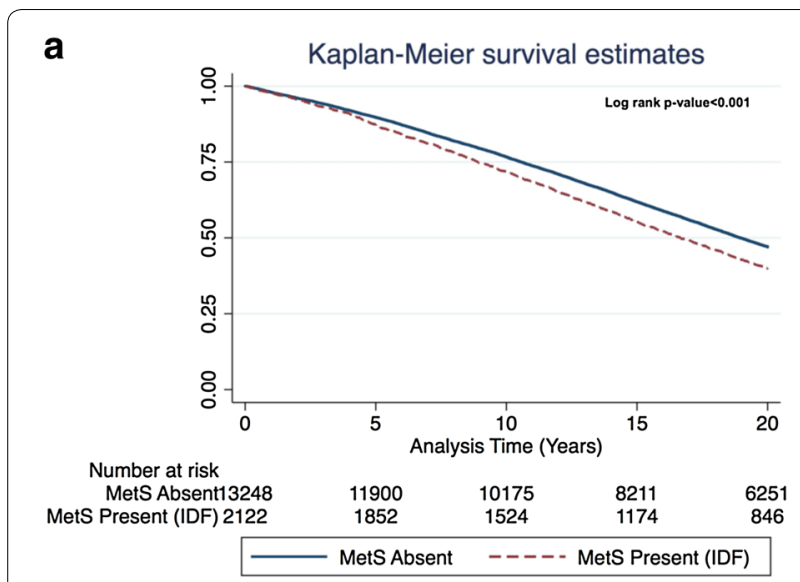

b

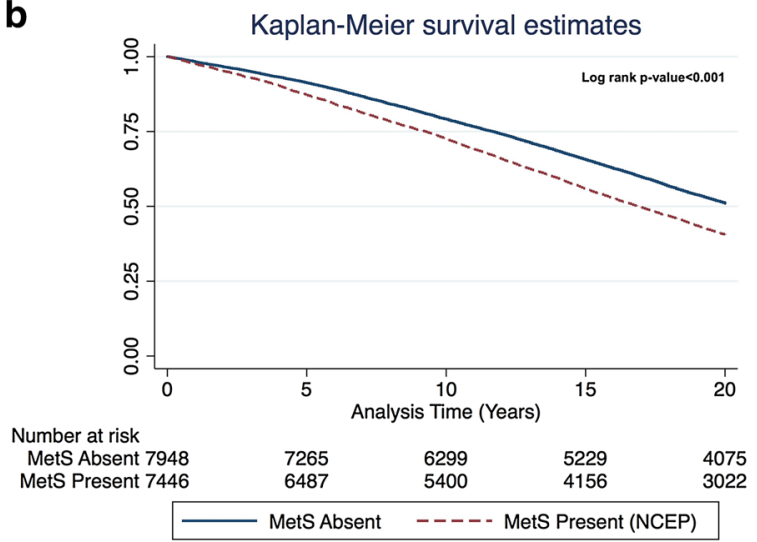

Fig. 1 Kaplan-Meier 20-year survival estimates for the entire cohort. a Survival estimates according to the presence or absence of the metabolic syndrome according to the IDF definition. b Survival estimates according to the presence or absence of metabolic syndrome according to the NCEP definition. Cre creatinine; DM diabetes mellitus; IDF International Diabetes Federation; LDL low density lipoprotein; MetS metabolic syndrome; MI myocardial infarction; NCEP National Cholesterol Educational Program

obtained when patients randomized to the interventional BIP trial $(n=3090)$ were excluded or when medications were adjusted for. The mortality risk associated with MetS was similar when BMI was excluded, and patients were defined based only on two out of remaining four criteria.

Increased serum creatinine, the presence of diabetes mellitus, current smoking and a history of myocardial infarction were additional independent predictors of allcause mortality (Table 2a, b).

\section{Subgroup analysis}

We further explored the independent association between the presence of MetS and long-term mortality in predefined subgroups of patients (Fig. 2). This analysis showed that the mortality risk was increased by $15-25 \%$ across all major groups when both definitions of MetS
Table 2 Independent all-cause mortality risk predictors in patients with stable CAD using the (a) NCEP and (b) IDF MetS definition

\begin{tabular}{lccc}
\hline & Adjusted HR & 95\% Cl for upper & P value \\
\hline (a) Hazard ration among the NCEP metabolic group & \\
Metabolic NCEP & 1.21 & $1.14-1.29$ & $<0.001$ \\
Age $>65$ years & 1.08 & $1.07-1.08$ & $<0.001$ \\
Male gender & 1.19 & $1.09-1.31$ & $<0.001$ \\
Creatinine $>1.5$ mg/dL & 1.59 & $1.38-1.84$ & $<0.001$ \\
Diabetes mellitus & 1.61 & $1.49-1.74$ & $<0.001$ \\
Hypertension & 1.08 & $1.01-1.15$ & 0.01 \\
Past Ml & 1.41 & $1.31-1.52$ & $<0.001$ \\
Previous CVA & 1.07 & $0.83-1.39$ & 0.59 \\
NYHA $>2$ & 1.25 & $1.10-1.43$ & $<0.001$ \\
Active smoker & 1.57 & $1.43-1.71$ & $<0.001$ \\
(b) Hazard ration among the IDF metabolic group & $1.07-1.28$ & $<0.001$ \\
Metabolic IDF & 1.17 & $1.08-1.09$ & $<0.001$ \\
Age $>65$ years & 1.08 & $1.06-1.29$ & $<0.001$ \\
Male gender & 1.17 & $1.38-1.84$ & $<0.001$ \\
Creatinine $>1.5$ mg/dL & 1.60 & $1.56-1.81$ & $<0.001$ \\
Diabetes mellitus & 1.68 & $1.04-1.18$ & 0.003 \\
Hypertension & 1.10 & $1.31-1.52$ & $<0.001$ \\
Past Ml & 1.41 & $0.85-1.42$ & 0.48 \\
Previous CVA & 1.10 & $1.07-1.41$ & 0.003 \\
NYHA $>2$ & 1.23 & $1.43-1.72$ & $<0.001$ \\
Active smoker & 1.57 & & \\
\hline Both & & & \\
\hline
\end{tabular}

Both models further adjusted for: hypertension, smoking status, and severe heart failure (NYHA >2)

CI 95\% confidence interval; CVA cerebral-vascular accident; $H R$ hazard ratio; MI myocardial infarction; NCEP National Cholesterol Education Program; IDF International Diabetes Federation; NYHA New York Heart Association

were used, with the exception of patients with creatinine concentration $>1.5 \mathrm{mg} / \mathrm{dL}$ ( $\mathrm{p}$ value of interaction $\mathrm{p}=0.04$ ) and those 65 years old or older, when NCEP definition was used ( $p$ value for interaction $=0.003$; Fig. 2a, b).

\section{Discussion}

The primary findings of our study are: (1) MetS is associated with approximately $20 \%$ greater all-cause mortality risk at 20-year of follow-up; the risk is independent of other important predictors of adverse outcomes; (2) The two leading definitions of MetS, respectively IDF and NCEP criteria, have similar long-term prognostic implications despite the inclusion of a much greater number of patients according to the NCEP definition; (3) the mortality risk associated with MetS is consistent in most patient subgroups, with the possible exception of those with renal dysfunction and less pronounced in patients aged 65 years or older. 


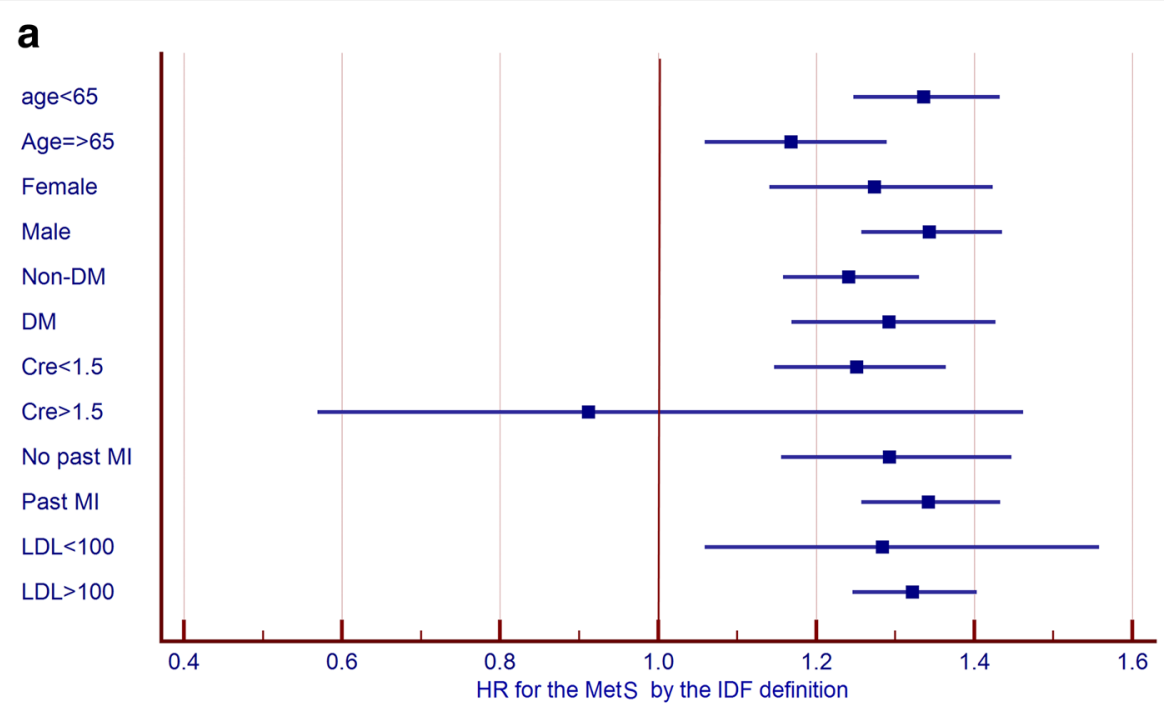

\begin{tabular}{|r|r|r|}
\hline \multicolumn{1}{|l|}{ HR } & Lower & Upper \\
\hline 1.336 & 1.247 & 1.432 \\
\hline 1.168 & 1.059 & 1.289 \\
\hline 1.274 & 1.141 & 1.423 \\
\hline 1.343 & 1.257 & 1.435 \\
\hline 1.241 & 1.158 & 1.33 \\
\hline 1.292 & 1.169 & 1.427 \\
\hline 1.251 & 1.147 & 1.364 \\
\hline 0.912 & 0.569 & 1.462 \\
\hline 1.293 & 1.156 & 1.447 \\
\hline 1.342 & 1.257 & 1.433 \\
\hline 1.284 & 1.059 & 1.558 \\
\hline 1.322 & 1.246 & 1.403 \\
\hline & & \\
\hline & & \\
\hline
\end{tabular}

b

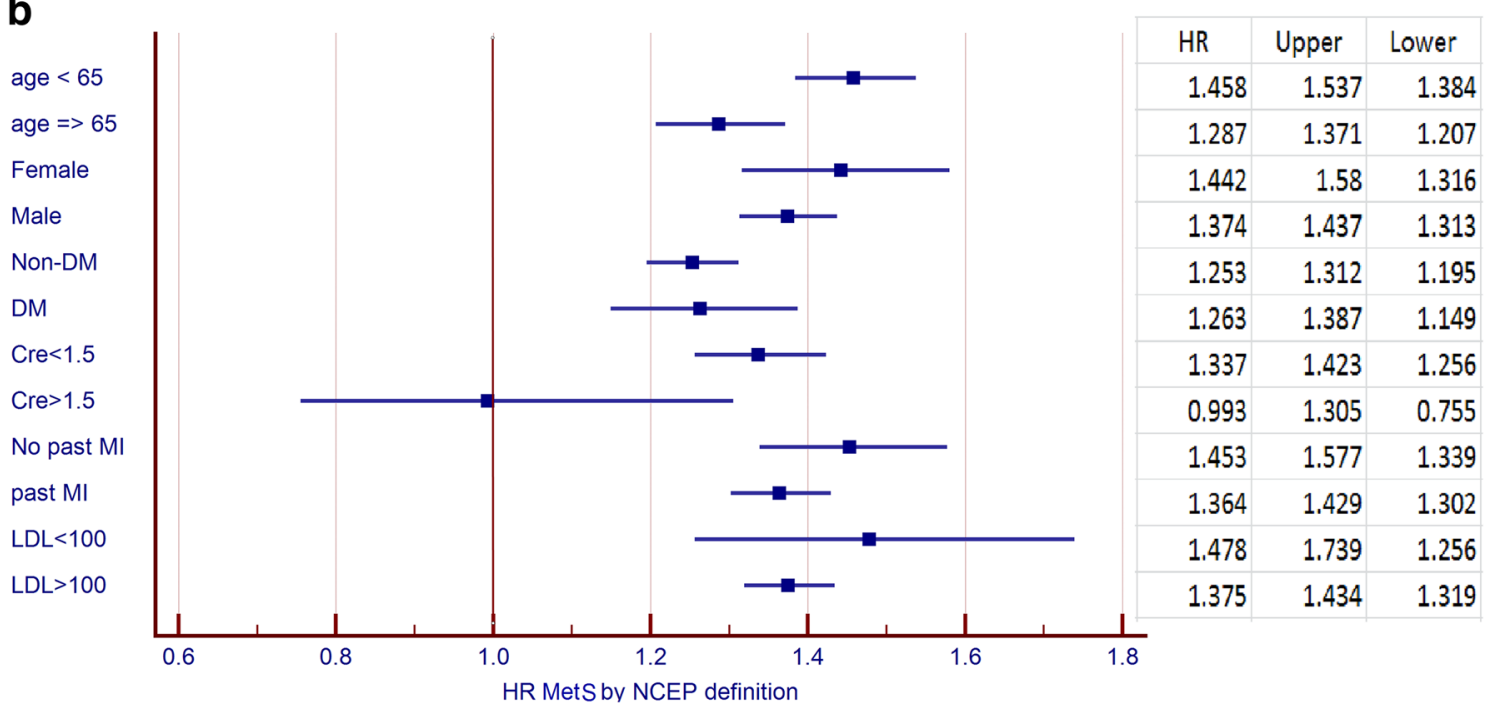

Fig. 2 Mortality risk associated with metabolic syndrome presence according to the IDF (a) and NCEP definitions (b) in pre-specified subgroups. Both models further adjusted for: hypertension, smoking status, and severe heart failure (NYHA >2). Cre creatinine; DM diabetes mellitus; IDF International Diabetes Federation; LDL low density lipoprotein; MetS metabolic syndrome; MI myocardial infarction; NCEP National Cholesterol Educa-

tional Program

A number of prior large-scale studies demonstrated the long-term prognostic significance of every single metabolic component of the MetS [15, 30-33], whereas controversy remains regarding additional value of the MetS in the risk estimation on top of its individual components [28, 34-39].

Although earlier studies tend to show a significant association between MetS and all-cause mortality especially among middle-aged individuals similar to our cohort, $[10,40-42]$ they were shorter in duration $[17,20,43,44]$, had smaller samples [45-47], had cardiovascular mortality as their primary outcome and comprised mostly of patients after an intervention [17, 20, 43-47]. In studies by Marso et al. and Miller et al. patients with acute coronary syndrome were enrolled, rather than patients with a stable coronary disease [32, 33].

On the other hand, more recent studies, who enrolled patients with ACS were unable to demonstrate such an association in coronary patients after ACS or revascularization. $[48,49]$.

The largest meta-analysis that included near one million patients (total $n=951,083$ ) concluded that the MetS is associated with a twofold increase in cardiovascular outcomes and a 1.5-fold increase in all-cause mortality 
rates [42]. Nevertheless, most subjects included in this analysis had no overt cardiovascular disease.

One recent large study by van Herpt et al. has shown that MetS increased the all-cause mortality in univariate analysis, yet was unable to find any significant associations of MetS with all-cause mortality after adjustment for age, gender and comorbidities. [39].

Additionally, previous studies were limited by their small size and relatively modest follow-up period, which was mostly less than 3 years in the majority of studies concerning the MetS and mortality. [16-21] Furthermore these studies have explored the cardiovascular mortality rather than all-cause mortality as their primary outcome. [16-21].

Hence the enrollment for this study took place between the years 1990 and 1992, the majority of the patients didn't undergo revascularization at the time of their enrollment. While most studies that evaluated patients after a recent acute coronary syndrome $[14,15,30]$ or after coronary revascularization [16-21] failed to show a significant effects of MetS on mortality among patients with stable coronary artery disease and without revascularization, our study did find a significant association with all-cause mortality.

To the best of our knowledge, our study is the largest and presents the longest follow-up period of patients with stable CAD demonstrating an independent association of MetS with all-cause mortality.

Despite the significant numeric difference, and the significant difference of their metabolic components, both MetS groups (IDF and NCEP definitions), had almost a similar effect on the 20-year all-cause mortality outcome, regardless of the definition employed.

Notably, the number of patients with MetS according to NCEP criteria was significantly larger than the number obtained when the IDF criteria were utilized (7446 vs. 2122). This difference is due to the obligatory inclusion of the central obesity as a required according to the IDF criteria, in addition to the two or more of the remaining 4 criteria detailed above. In contrast, the NCEP does not present such an obligatory requirement and is based on the presence of any three criteria. This leads to the fact that all IDF patients are also included in the NCEP group.

Despite the fact that the presence of the MetS possesses a definite predictive value, the view of this metabolic cluster as a prognostic tool only will be too simplistic. MetS is a widely accepted concept regarding a biological condition based on the complex and interrelated pathophysiological mechanisms starting from excess central adiposity and insulin resistance. MetS identifies additional important residual vascular risk mainly associated with insulin resistance, atherogenic dyslipidemia, non-alcoholic fatty liver and type 2 diabetes development. Therefore, the MetS could be a useful additional contributor in estimation of global cardiovascular risk beyond its components and other standard risk factors like age, high LDL-C, etc. [50-55].

Moreover, the concept that the metabolic syndrome is a consequence of obesity and insulin resistance, provides a useful "life-style changes" approach for prevention and treatment: caloric restriction, weight-loss and increased physical activity within cardiac rehabilitation programs for patients with CAD.

\section{Limitations}

Our study has a number of limitations. First, it is a retrospective study that enrolled patients during a period where different treatments were used for controlling blood glucose, hyperlipidemia and hypertension, thus our results warrant validation in more contemporary populations. Second, not all confounders can be accounted for nor were all possible variables measured at enrolment. Third, we have no data regarding clinical events and clinical management after the screening period. Finally, our data lacks waist circumference assessment which is important element of the definition of central obesity as a component of the MetS. However, we replaced this criteria with the $\mathrm{BMI}>30$ according to the consensus of the IDF and NCEP. Furthermore, when we excluded the BMI criteria, and set the diagnosis of MetS as the presence of two out the four remaining criteria, similar results were obtained.

\section{Conclusions}

Metabolic syndrome is independently associated with increased 20-year mortality in patients with stable coronary artery disease. The excess of the very long-term mortality risk was consistent regardless of the MetS definition employed and similar across most population subgroups, yet less pronounced in patients of 65 year or older and absent in patients with renal failure.

\section{Additional file}

Additional file 1: Table S1. Differences between the MetS definitions in terms of their individual components.

\section{Abbreviations}

BIP: Bezafibrate Infarction Prevention; BMI: body mass index; CABG: coronary artery bypass grafting; CAD: coronary artery disease; COPD: chronic obstructive pulmonary disease; CVA: cerebral vascular accident; DM: diabetes mellitus; FPG: fasting plasma glucose; HDL: high-density lipoprotein; HTN: hypertension; IDF: International Diabetes Federation; LDL: Iow density lipoprotein; LML: log minus log; MetS: metabolic syndrome; MI: myocardial infarction; NCEP: National Cholesterol Educational Program; NYHA: New York Heart Association; PTCA: percutaneous transluminal coronary angioplasty; SD: standard deviation; TG: triglycerides. 


\section{Authors' contributions}

ArY and RK designed the study, developed the methodology, analyzed the data and wrote the manuscript. AnY, IG, analyzed and interpreted the patien data, revised the manuscript, and contributed to the writing. NS was a major contributor in the statistical analysis. BT, YP and EZF helped with the collecting of the data. AT was a major contributor in writing the manuscript and analyzing the results. All authors read and approved the final manuscript.

\section{Author details}

1 The Leviev Heart Center, Sheba Medical Center, Tel Hashomer, Sheba Road 2, 52620 Ramat Gan, Israel. ${ }^{2}$ Sakler School of Medicine, Tel Aviv University, Ramat Gan, Israel. ${ }^{3}$ Cardiovascular Diabetology Research Foundation, Holon, Israel. ${ }^{4}$ Heart Research Follow-up Program, University of Rochester, Rochester, NY, USA.

\section{Acknowledgements}

The study was made possible by the combined efforts of the BIP study group and the Israeli Association for Cardiovascular Trials.

\section{Competing interests}

EZF and AT are Editors-in-Chief of Cardiovascular Diabetology. All other authors declare that they have no competing interests.

\section{Availability of data and material}

The datasets during and/or analysed during the current study available from the corresponding author on reasonable request.

\section{Ethics approval and consent to participate}

The study was approved by the Sheba institute's internal review board and was performed according to the principles expressed in the Declaration of Helsinki and the ethics policy of the Sheba Medical Center.

Received: 21 July 2016 Accepted: 20 October 2016

Published online: 28 October 2016

\section{References}

1. Wilson PW, Grundy SM. The metabolic syndrome: practical guide to origins and treatment: Part I. Circulation. 2003;108(12):1422-4.

2. Wilson PW, Grundy SM. The metabolic syndrome: a practical guide to origins and treatment: Part II. Circulation. 2003;108(13):1537-40.

3. Ford ES. Prevalence of the metabolic syndrome in US populations. Endocrinol Metab Clin North Am. 2004;33(2):333-50.

4. Ford ES, Giles WH, Mokdad AH. Increasing prevalence of the metabolic syndrome among US Adults. Diabetes Care. 2004;27(10):2444-9.

5. Hu G, Lindstrom J, Jousilahti P, Peltonen M, Sjoberg L, Kaaja R, Sundvall J, Tuomilehto J. The increasing prevalence of metabolic syndrome among Finnish men and women over a decade. J Clin Endocrinol Metab. 2008;93(3):832-6.

6. Lim S, Shin H, Song JH, Kwak SH, Kang SM, Won Yoon J, Choi SH, Cho SI, Park KS, Lee HK, et al. Increasing prevalence of metabolic syndrome in Korea: the Korean National Health and Nutrition Examination Survey for 1998-2007. Diabetes Care. 2011;34(6):1323-8.

7. Eckel RH, Grundy SM, Zimmet PZ. The metabolic syndrome. Lancet. 2005;365(9468):1415-28.

8. Nikolopoulou A, Kadoglou NP. Obesity and metabolic syndrome as related to cardiovascular disease. Expert Rev Cardiovasc Ther. 2012:10(7):933-9.

9. Isomaa B, Almgren P, Tuomi T, Forsen B, Lahti K, Nissen M, Taskinen MR Groop L. Cardiovascular morbidity and mortality associated with the metabolic syndrome. Diabetes Care. 2001;24(4):683-9.

10. Lakka HM, Laaksonen DE, Lakka TA, Niskanen LK, Kumpusalo E, Tuomilehto J, Salonen JT. The metabolic syndrome and total and cardiovascular disease mortality in middle-aged men. JAMA. 2002;288(21):2709-16.

11. Ninomiya JK, L'Italien G, Criqui MH, Whyte JL, Gamst A, Chen RS. Association of the metabolic syndrome with history of myocardial infarction and stroke in the Third National Health and Nutrition Examination Survey. Circulation. 2004;109(1):42-6.
12. Obunai K, Jani S, Dangas GD. Cardiovascular morbidity and mortality of the metabolic syndrome. Med Clin North Am. 2007;91(6):1169-84 (x)

13. Thomas GN, Schooling CM, McGhee SM, Ho SY, Cheung BM, Wat NM, Janus ED, Lam KS, Lam TH. Hong Kong Cardiovascular risk factor prevalence study steering C: metabolic syndrome increases all-cause and vascular mortality: the Hong Kong Cardiovascular Risk Factor Study. Clin Endocrinol. 2007;66(5):666-71.

14. Kul S, Uyarel H, Gul M, Kucukdagli OT, Bacaksiz A, Erdogan E, Ekmekci A. Metabolic syndrome and long-term cardiovascular outcomes in NSTEMI with unstable angina. Nutr Metab Cardiovasc Dis. 2014;24(2):176-82.

15. Arbel Y, Havakuk O, Halkin A, Revivo M, Berliner S, Herz I, Weiss-Meilik A, Sagy Y, Keren G, Finkelstein A, et al. Relation of metabolic syndrome with long-term mortality in acute and stable coronary disease. Am J Cardiol. 2015;115(3):283-7

16. Tie HT, Shi R, Li ZH, Zhang M, Zhang C, Wu QC. Risk of major adverse cardiovascular events in patients with metabolic syndrome after revascularization: A meta-analysis of eighteen cohorts with 18,457 patients. Metabolism. 2015;64(10):1224-34

17. Iturry-Yamamoto GR, Zago AC, Moriguchi EH, Manfroi WC, Camargo $J \mathrm{~L}$, Gross JL, Zago AJ. Impact of metabolic syndrome and C-reactive protein on outcome after coronary stenting. J Endocrinol Invest. 2009:32(4):383-6.

18. Akman T, Binbay M, Erbin A, Tepeler A, Sari E, Kucuktopcu O, Ozgor F, Muslumanoglu A. The impact of metabolic syndrome on long-term outcomes of percutaneous nephrolithotomy (PCNL). BJU Int. 2012;110(11 Pt C):E1079-83.

19. Angeloni E, Melina G, Benedetto U, Refice S, Capuano F, Roscitano A, Comito C, Sinatra R. Metabolic syndrome affects midterm outcome after coronary artery bypass grafting. Ann Thorac Surg. 2012;93(2):537-44.

20. Uchida Y, Ichimiya S, Ishii H, Kanashiro M, Watanabe J, Yoshikawa D, Takeshita K, Sakai S, Amano T, Matsubara T, et al. Impact of metabolic syndrome on various aspects of microcirculation and major adverse cardiac events in patients with ST-segment elevation myocardial infarction. Circ J. 2012;76(8):1972-9.

21. Ivanovic B, Tadic M, Bradic Z, Zivkovic N, Stanisavljevic D, Celic V. The influence of the metabolic syndrome on atrial fibrillation occurrence and outcome after coronary bypass surgery: a 3-year follow-up study. Thorac Cardiovasc Surg. 2014;62(7):561-8.

22. Lipids and lipoproteins in symptomatic coronary heart disease. Distribution, intercorrelations, and significance for risk classification in 6700 men and 1500 women. The Bezafibrate Infarction Prevention (BIP) Study Group, Israel. Circulation. 1992:86(3):839-48.

23. Goldbourt U, Behar S, Reicher-Reiss H, Agmon J, Kaplinsky E, Graff E, Kishon Y, Caspi A, Weisbort J, Mandelzweig L, et al. Rationale and design of a secondary prevention trial of increasing serum high-density lipoprotein cholesterol and reducing triglycerides in patients with clinically manifest atherosclerotic heart disease (the Bezafibrate Infarction Prevention Trial). Am J Cardiol. 1993;71(11):909-15.

24. International Diabetes Federation. Medicine on the net. 2014; 20(5):10. http://www.idf.org/webdata/docs/IDF_Meta_def_final.pdf. Accessed 11 Oct 2005.

25. Zimmet P, Alberti KG, Rios MS. A new international diabetes federation worldwide definition of the metabolic syndrome: the rationale and the results. Rev Esp Cardiol. 2005;58(12):1371-6.

26. Grundy SM, Cleeman II, Daniels SR, Donato KA, Eckel RH, Franklin BA, Gordon DJ, Krauss RM, Savage PJ, Smith SC Jr, et al. Diagnosis and management of the metabolic syndrome: an American Heart Association/ National Heart, Lung, and Blood Institute Scientific Statement. Circulation. 2005;112(17):2735-52.

27. Dekker JM, Girman C, Rhodes T, Nijpels G, Stehouwer CD, Bouter LM, Heine RJ. Metabolic syndrome and 10-year cardiovascular disease risk in the Hoorn Study. Circulation. 2005;112(5):666-73.

28. Alberti KG, Eckel RH, Grundy SM, Zimmet PZ, Cleeman II, Donato KA, Fruchart JC, James WP, Loria CM, Smith SC Jr, et al. Harmonizing the metabolic syndrome: a joint interim statement of the International Diabetes Federation Task Force on Epidemiology and Prevention; National Heart, Lung, and Blood Institute; American Heart Association; World Heart Federation; International Atherosclerosis Society; and International Association for the Study of Obesity. Circulation. 2009;120(16):1640-5. 
29. Bezafibrate Infarction Prevention. Secondary prevention by raising HDL cholesterol and reducing triglycerides in patients with coronary artery disease. Circulation. 2000;102(1):21-7.

30. Timmer JR, Hoekstra M, Nijsten MW, van der Horst IC, Ottervanger JP, Slingerland RJ, Dambrink JH, Bilo HJ, Zijlstra F, van't Hof AW. Prognostic value of admission glycosylated hemoglobin and glucose in nondiabetic patients with ST-segment-elevation myocardial infarction treated with percutaneous coronary intervention. Circulation. 2011;124(6):704-11.

31. Kim HK, Kim CH, Kim EH, Bae SJ, Choe J, Park JY, Park SW, Yun YD, Baek SJ, Mok Y, et al. Impaired fasting glucose and risk of cardiovascular disease in Korean men and women: the Korean Heart Study. Diabetes Care. 2013;36(2):328-35.

32. Klempfner R, Erez A, Sagit BZ, Goldenberg I, Fisman E, Kopel E, Shlomo $\mathrm{N}$, Israel A, Tenenbaum A. Elevated triglyceride level is independently associated with increased all-cause mortality in patients with established Coronary Heart Disease: twenty-two-year follow-up of the Bezafibrate Infarction Prevention Study and Registry. Circ Cardiovasc Qual Outcomes. 2016;9(2):100-8.

33. Tenenbaum A, Klempfner R, Fisman EZ. Hypertriglyceridemia: a too long unfairly neglected major cardiovascular risk factor. Cardiovasc Diabetol. 2014;13:159.

34. Sattar N, McConnachie A, Shaper AG, Blauw GJ, Buckley BM, de Craen AJ, Ford I, Forouhi NG, Freeman DJ, Jukema JW, et al. Can metabolic syndrome usefully predict cardiovascular disease and diabetes? Outcome data from two prospective studies. Lancet. 2008;371(9628):1927-35.

35. Rachas A, Raffaitin C, Barberger-Gateau P, Helmer C, Ritchie K, Tzourio C, Amouyel P, Ducimetiere P, Empana JP. Clinical usefulness of the metabolic syndrome for the risk of coronary heart disease does not exceed the sum of its individual components in older men and women. The Three-City (3C) Study. Heart. 2012;98(8):650-5.

36. Ahmadi A, Leipsic J, Feuchtner G, Gransar H, Kalra D, Heo R, Achenbach S, Andreini D, Al-Mallah M, Berman DS, et al. Is metabolic syndrome predictive of prevalence, extent, and risk of coronary artery disease beyond its components? Results from the multinational coronary $\mathrm{CT}$ angiography evaluation for clinical outcome: an international multicenter registry (CONFIRM). PLoS ONE. 2015;10(3):e0118998.

37. Kotani K, Satoh-Asahara N, Nakakuki T, Yamakage H, Shimatsu A, Tsukahara T. Association between metabolic syndrome and multiple lesions of intracranial atherothrombotic stroke: a hospital-based study. Cardiovasc Diabetol. 2015:14:108.

38. Georgiopoulos G, Tsioufis C, Tsiachris D, Dimitriadis K, Kasiakogias A, Lagiou F, Andrikou E, loannidis I, Hatziagelaki E, Tousoulis D. Metabolic syndrome, independent of its components, affects adversely cardiovascular morbidity in essential hypertensives. Atherosclerosis, 2016;244:66-72

39. van Herpt TT, Dehghan A, van Hoek M, Ikram MA, Hofman A, Sijbrands $\mathrm{EJ}$, Franco $\mathrm{OH}$. The clinical value of metabolic syndrome and risks of cardiometabolic events and mortality in the elderly: the Rotterdam study. Cardiovasc Diabetol. 2016;15(1):69.

40. Marso SP, Mercado N, Maehara A, Weisz G, Mintz GS, McPherson J, Schiele F, Dudek D, Fahy M, Xu K, et al. Plaque composition and clinical outcomes in acute coronary syndrome patients with metabolic syndrome or diabetes. JACC Cardiovasc Imaging. 2012;5(3 Suppl):S42-52.

41. Ford ES. Risks for all-cause mortality, cardiovascular disease, and diabetes associated with the metabolic syndrome: a summary of the evidence. Diabetes Care. 2005;28(7):1769-78.
42. Mottillo S, Filion KB, Genest J, Joseph L, Pilote L, Poirier P, Rinfret S, Schiffrin EL, Eisenberg MJ. The metabolic syndrome and cardiovascular risk a systematic review and meta-analysis. J Am Coll Cardiol. 2010;56(14):1113-32.

43. Kim JS, Lee HC, Choi BK, Lee HW, Park JS, Lee YH, Ahn MS, Hong TJ, Kim SP, Lee SK, et al. Impact of metabolic syndrome on in-stent restenosis and clinical outcomes after percutaneous coronary stent implantation. Diabetes Res Clin Pract. 2010;88(3):e38-41.

44. Lee MG, Jeong MH, Ahn Y, Chae SC, Hur SH, Hong TJ, Kim YJ, Seong IW, Chae JK, Rhew JY, et al. Impact of the metabolic syndrome on the clinical outcome of patients with acute ST-elevation myocardial infarction. J Korean Med Sci. 2010;25(10):1456-61.

45. Dohi T, Miyauchi K, Kasai T, Kajimoto K, Kubota N, Tamura H, Yokoyama T, Kojima T, Yokoyama K, Kurata T, et al. Impact of metabolic syndrome on 10-year clinical outcomes among patients with acute coronary syndrome. Circ J. 2009:73(8):1454-8.

46. Kasai T, Miyauchi K, Kajimoto K, Kubota N, Yanagisawa N, Amano A, Daida $\mathrm{H}$. Relationship between the metabolic syndrome and the incidence of stroke after complete coronary revascularization over a 10-year follow-up period. Atherosclerosis. 2009;207(1):195-9.

47. Kunimura A, Amano T, Uetani T, Harada K, Yoshida T, Suzuki A, Shimbo Y, Kitagawa K, Harada K, Kato B, et al. Prognostic impact of concurrence of metabolic syndrome and chronic kidney disease in patients undergoing coronary intervention: involvement of coronary plaque composition. J Cardiol. 2013;61(3):189-95.

48. Babic Z, Pavlov M, Bulj N, Heitzler VN, Mitrovic V, Hamm C, Weber M. Metabolic syndrome and outcome in patients with acute myocardial infarction. Acta Clin Croat. 2011;50(2):193-9.

49. Hoffmann R, Stellbrink E, Schroder J, Grawe A, Vogel G, Blindt R, Kelm $M$, Radke PW. Impact of the metabolic syndrome on angiographic and clinical events after coronary intervention using bare-metal or sirolimuseluting stents. Am J Cardiol. 2007;100(9):1347-52.

50. Tenenbaum A, Motro M, Schwammenthal E, Fisman EZ. Macrovascular complications of metabolic syndrome: an early intervention is imperative. Int J Cardiol. 2004:97(2):167-72.

51. Eckel RH, Alberti KG, Grundy SM, Zimmet PZ. The metabolic syndrome. Lancet. 2010;375(9710):181-3.

52. Tenenbaum A, Fisman EZ. "The metabolic syndrome... is dead": these reports are an exaggeration. Cardiovasc Diabetol. 2011;10:11.

53. Hallberg V, Palomaki A, Lahtela J, Voutilainen S, Tarkka S, Kataja M, Study Group (W-CABG). Associations of metabolic syndrome and diabetes mellitus with 16-year survival after CABG. Cardiovasc Diabetol. 2014;13:25

54. Du T, Yu X, Yuan G, Zhang J, Sun X. Combined influence of nonalcoholic fatty liver and body size phenotypes on diabetes risk. Cardiovasc Diabetol. 2015;14:144

55. Grams J, Garvey WT. Weight loss and the prevention and treatment of type 2 diabetes using lifestyle therapy, pharmacotherapy, and bariatric surgery: mechanisms of action. Curr Obes Rep. 2015:4(2):287-302.

\section{Submit your next manuscript to BioMed Central and we will help you at every step:}

- We accept pre-submission inquiries

- Our selector tool helps you to find the most relevant journal

- We provide round the clock customer support

- Convenient online submission

- Thorough peer review

- Inclusion in PubMed and all major indexing services

- Maximum visibility for your research

Submit your manuscript at www.biomedcentral com/submit
BioMed Central 